\title{
Features of Formation of Future Educational Psychologists' Professional Identity during Their Retraining
}

\author{
Svetlana E. Chirkina ${ }^{1}$ \\ ${ }^{1}$ Kazan (Volga region) Federal University, Kazan, Russia \\ Correspondence: Svetlana E. Chirkina, Kazan (Volga region) Federal University, Kremlyovskaya Street 18, \\ Kazan, 420008, Russia.
}

Received: October 24, 2014 Accepted: December 3, 2014 Online Published: December 18, 2014

doi:10.5539/res.v7n1p161 URL: http://dx.doi.org/10.5539/res.v7n1p161

\begin{abstract}
The actuality of the problem's research is caused by conditions of three kinds: firstly, the increasing demand for the profession and humanistic values of the practical psychologist in education; secondly, the special circumstances of the accelerated training of psychologists (from former teachers), who are actually taking possession of a new profession; thirdly, the lack of research, where the impact of training on professional identity is studied. The purpose of the article is to uncover the structure of future educational psychologists' professional notions, identifying the occurrence period of their basic elements ("standard frame") of professional-psychological picture of the world, establishing the peculiarities of professional outlook. The leading method of study of this problem is ascertaining experiment. As a result the structure and genesis of professional psychological image of the world of the future educational psychologists was revealed. The materials of the article are of great value to the organizers of professional retraining of educational psychologists, academics, as well as valuable in the development of recommendations regarding formation of policies in the sphere of additional education in "Practical Psychology in Education".
\end{abstract}

Keywords: professional retraining of educational psychologists, professional competence, professional identity, structure and genesis of professional psychological image of the world

\section{Introduction}

In the context of non-guaranteed employment, the transition to a free labor market, the problem of professional reorientation of adults is becoming one of the most important in the life of society. Excluding the transition from one profession to another, adequate assessment of individuals and their opportunities prevailing in a certain stage of professional and personal development, psychological characteristics of previous and new activities, forecasting the capabilities of its successful development to solve the problem of the reorientation of adults may not be effective enough. The possibilities of the development of professionally important human personality structures, the "new" professional self-awareness, understanding of the characteristics of the genesis of man's replacement of his profession are not fully explored.

A particular case of this problem is the retraining of educational psychologists from the teachers. The reforming of the system of education in Russia led to the development of practical psychology of education. Currently, the development strategy of the service of practical psychology of education, training and professional development of educational psychologists is being actively reinterpreted (Dubrovina, 1991, 2004; Zabrodin, 1989, 2013; Rubtsov, 2007; Chirkina 2014). Acutely arise the problems of their professional competence (Pahalyan, 2002, 2003; Khusainova, 2014; Masalimova, 2008), the adequacy of professional consciousness (Klimov, 1996; Bajanova \& Habutdinova, 2013), revealing the structure and genesis of their professional and psychological image of the world.

\section{Materials and Methods}

In the process of solving the tasks, a set of techniques that identify the properties of subject-activity and communicative aspects of temperament (questionnaire by V. M. Rusalov), the nature of personal factors (16 F R. Cattell), the man's conception about himself, as a professional (a projective technique "Me - a professional in the present and the future," the technique "Associative halo of the profession" E. A. Klimov, the technique "Evaluation of professional development") was used. 
Vital orientations were investigated using the test developed and adapted by D. A. Leontiev, which is based on the PIL test. (Purpose-in-Life Test) J. Crumbo and L. Macholik. Self-treatment was studied with the help of the technique proposed by V. V. Stalin and S. R. Pantileev.

The obtained data were subjected to the correlation analysis. The processing of the answers to open questions in the questionnaire was carried out by means of content analysis procedures and frequency of semantic analysis.

\section{Results and Discussions}

\subsection{Features of the Formation of Professional Identity}

The correlation analysis of the results of research on the impact of training professional identity of teachers-psychologists (former teachers) showed that the nature of the relationships between the personal characteristics of the teacher (before studying at the faculty), educational psychologist (after training at the faculty) and practical educational psychologist (working psychologists) expressed different specific features, traced the presence of positive and negative relationships between measures of personality traits, cognitive level of professional consciousness and affective level of professional consciousness.

However, the attention is drawn to the first stage of the experiment, where the subgroup №1 (teachers before studies) has no interdependence in terms of cognitive and affective levels of professional consciousness, that is quite logical, concerning the mastering of the profession of psychologist, as the training has not yet passed and the examinees could not adequately give themselves a total professional self-esteem, to evaluate the professional level of self-efficacy, although at this stage the examinees evaluated the professional image 'Self' sufficiently (future self), tying their future competence with practical psychology of education, with the concepts of professional self-image (real and ideal self).

In the person of the teacher (the future psychologist) before studies are presented the relationships between such properties as communication and organizational aptitude, aspiration for innovation, experimentation, openness, cheerfulness, need for achievement, empathy.

In the functioning of the relationships between personality traits an important role play his organizational tendencies, which are needed in the profession. The relationships' character of such properties as openness, sociability, the commitment of groups, social boldness, stress steadiness in communication, communicative gifts becomes more pronounced.

In subgroup №2 (educational psychologists — the graduates of vocational training) is already observed strong relationship between overall professional self-esteem and adequate professional image "Self"-ideal and "Self"-real, also the indicators of these levels are positively correlated with the indicators of personality. In the personality of psychologists of this group are presented the relationships with such property as tension, frustration, which manifests itself as a result of mastering a new profession, personal adjustment formations.

Furthermore, in this subgroup intensive significant correlation relatioships between indices of cognitive, affective and personal levels are observed. Emphasis is placed on the relationships between the overall index of professional self-esteem with the index of professional performance, presentation of "Self" images (former professional "Self" image and the future of the professional "Self" image), "Self"-real and "Self"-ideal, with the examinee's level of intelligence, expressive, normative behavior, and others.

Based on the analysis of the results described above we can draw the following conclusion.

The activities of the teacher and the practical psychologist of the education differ substantially in content, psychological structure and required professional qualities. Educational activity assumes ownership of teaching technologies and is aimed at creating educational skills, ability to learn, its development in the educational activity.

Professional knowledge and skills of the psychologist are related to his psychological culture and possession of psychotechnologies. The aim of the practical psychologist of education is to ensure conditions for the full development of the child's identity, optimal implementation of his capabilities, the ability to self-development. The activities of the teacher and psychologist is different in professional positions, attitudes towards the child. In view of the above, the profession of teacher-psychologist (practical psychologist of education) is new to the former teacher and produces the other professional requirements.

\subsection{The Influence of Professional Concepts on the Development of Educational Psychologist's Individuality} (Former Teacher)

This study was conducted in three phases. 
In the first phase were studied pre-scientific conceptions of students of the Faculty of retraining in the context of psychology teaching. The conversation began with the fact that every man, even if he never specifically studied psychology, has some psychological conceptions, which are called pre-scientific. Matrix included the following scientific concepts: psyche, consciousness; observation, experiment; personality, activity; need, motive; perception, thinking; emotions, feelings.

It is clearly seen that each pair includes the concepts that are in the logical connection. It was interesting to learn to what extent the students will reflect this connection (with no hint of its existence). The resulting materials were processed by the method of content analysis. The desire to construct a definition of the concept through the nearest generic concept (NGC) and species differences are seen in the vast majority of works.

Subsequently, we were interested to know to what extent the responses reflect the content of the scientific concepts. This was the level of disclosure of the concept's content.

Level 0 - unsuccessful definition.

Level I—element definition——was assigned if the response "clutched" some element of the scientific definition, the notion of sign.

Level II-fragmentary definition - took place when a part of the scientific signs was reflected in everyday concept.

Level III-definition with any inaccuracies, that's why incomplete.

Level IV - full, practically relevant to the scientific definition.

We immediately note that the IV level in the analysis of listeners' statements was never "needed", III-was rarely detected, the main "working" levels were 0 , I, II. Also the factor of the reproduction of the scientific definition in the everyday concept was introduced. In fact, the set response level was divided into the maximum possible (IV).

You can point to some ways of using existing materials in the teaching of psychology at retraining.

Firstly, to speak about accents rightfully relating to the content of teaching.

Secondly, the data on everyday psychological conceptions may determine methods of development of scientific concepts. For example, the definition of necessity as an experienced need is advisable to put in place of the unknown in a problem situation, and the probability model of the organization of the search is relatively easily constructed precisely in view of everyday perceptions of listeners. In the process of resolving the problem situation occurs as the reliance on these conceptions and their contrasting to scientific certainties. In other cases, the focus on pre-scientific knowledge helps to develop heuristic conversations, compose text psychological tasks for independent work of students. All of this can be seen as a factor motivating educational and professional activity of future psychologists.

Thirdly, we obtained the data in favor of a series of didactic measures, which educate students' attitude to psychological knowledge as to the knowledge of useful, that is necessary to organize their own learning and life in general. The most favorable conditions in this plan contain so-called quasiprofessional forms of academic work (modeling of research procedures, training forms, fragments of business games and others), in which the unity of knowledge and action speaks very clearly.

\subsection{Features of the Professional Conception of Future Psychologists}

Problem field of our study was set with the attempts to answer the following questions:

- Are there any professional conceptions of psychologists?

- If yes, then:

- What are they?

- When do they arise?

- How do they change during the training?

- What are the determinants of professional conceptions?

Following the tradition of the study of social conceptions as sustainable forms of collective consciousness, and taking into account the experience of the research of professional mentality, a system of professional psychologists' conceptions we consider as consisting of two main interrelated subsystems: subjective and objective. The first one is formed by a set of conceptions of experts on the subject of psychology as a professional activity, the second predetermined the set of ideas about the content of the activities of such individual psychological characteristics of the respondents, as the meaning of life and the self-orientation. 
Analyzing the data, which is obtained with all these procedures, we sought to: 1) identify common characteristics of professional concepts common to all respondents; 2) to establish the specificity of conceptions by comparing groups of respondents; 3 ) determine the dynamics of the professional consciousness of students in the learning process, which required to compare the students' responses of the initial and the final stage of training, and compare the dynamics of these responses with those of teachers; 4) to examine individual psychological characteristics of personality of students of different periods of study and teachers.

Summing up the results of the studies of subject activity conceptions, it can be noted that from all respondents domineering ones were two groups of motivations for the Special Department of Psychology admission:

1) The desire to help people, to "humanize"the society;

2) The intention to solve their own problems, to ensure personal growth and self-development.

Data obtained using questionnaires suggest that listeners are peculiar:

- Positive evaluation of oneself as a whole, its qualities and perspectives that leads to a positive self-concept;

- Acceptable level of internal honesty and openness to ourselves and others;

- Awareness of the rules, regulations as benchmarks to assess their qualities;

- The ability to control and manage their own emotions, desires, and feelings;

- The desire for self-development and self-change at the middle expression of self-criticism and reflexivity.

Data obtained through the methods of vital orientation, indicate:

- Figures of men and women in all subgroups are high, and the general meaningfulness of life, and some of its aspects are valued highly;

- Found that the indices of men over all scales slightly are higher than women;

- Set some differences of characteristics of the first year students and graduates on subscales "purpose of life" and "locus of control".

\section{Conclusion}

Overall, the study allowed to draw the following conclusions. Found that the structure of professional psychologists' conceptions is, at least, two-component, and includes:

1) The conception of the subject of professional activities, including motivation in psychology studies, professional qualities and abilities of expert-psychologist, his appearance, etc;

2) The conception of the content of the activities, in particular on its object, purpose, resources.

The professional outlook of psychologists is at least of two levels and comprises relatively divergent ("superficial") conceptions, as well as more stable representative "core". There is a basis to believe that substantive conceptions are actually related to the "nuclear" ones - the prototype of results and ways to achieve them: they set the configuration used by professionals of categorical evaluation schemes of psychic reality.

It is confirmed that the professional conceptions of psychologists perform the following functions:

- Knowledge of the tool, i.e. the description (identification), classification and explanation (understanding) of mental phenomena;

- Adaptive function of conceptions, which are manifested in smoothing unusual, unexpected phenomena by introducing them to the usual system of values. Cognitive disequilibrium of the specialist caused by the appearance of a new object can be restored by the means of decomposition of the object on the known perceptual components, or, conversely, connecting it with chain links with familiar images and concepts through analogies and associations;

- The function of expression, allows professionals to feel like the owner of "secret knowledge", "engineers of human souls" that promotes self-concept and protection from criticism and encroachment by non-specialists;

- The function of social identification, i.e. the feeling (awareness) of belonging to a professional "department" of psychologists, enabling professional communication, recognition, and so on.

It is revealed that the main elements ("skeleton model") of the professional psychological picture of the world occur in the initial period of professional self-determination of the individual and do not undergo radical qualitative changes in the process of further professional socialization. 
It is established that professional psychologists' worldview is formed at the interface of scientific theoretical and practical knowledge of worldly-psychological nature of man and society, so that it differs with internal contradictions, eclectic, using the ordinary schemes of interpretation of psychological reality and the stereotypes.

Thus, the purpose of the study to identify the structure and genesis of professional psychological image of the world is mostly achieved. Of course, the "responsibility" for the identified features of professional consciousness and self-consciousness of psychologists - students of the faculty is not only on themselves or their teachers, but also on the state of psychology as such. Building a holistic, integrative psychological theory and overcoming its separation from the practice still remains the task of the future.

\section{References}

Bayanova, L. F., \& Khabutdinova, M. (2013). Norms and Values Characteristics of Students in a Foreign Cultural Environment. Middle-East Journal of Scientific Research, 16(11), 1527-1531.

Chirkina, S. E. (2014). Motives of training activities as a factor of the adults training efficiency during the vocational retraining. Life Science Journal, 11(12), 444-447.

Demin, V. A. (2000). Professional competence of a specialist: Concept and types. Standards and monitoring in education, 4, 34-42.

Dubrovina, I. V. (1991). Workbook school psychologist (p. 303). M: Education.

Dubrovina, I. V. (2004). Practical psychology of education (p. 592). SPb: Peter.

Ivanova, L. F. (2003). Innovative conditions for the development of professional competence of a teacher. Innovations in education, 4, 69-80.

Khusainova, R. M. (2014). Factors of Teachers' Psychological Health-Ailment within the Period of Their Professional Activity. World Applied Sciences, 30(5), 608-611.

Klimov, E. A. (1996). Psychology of professional self-determination (p. 312). R.N.E.

Masalimova, A. R. (2008). Formation of academic mobility of students of higher technical school abroad: Ideas, principles, performance criteria. Engineering Pedagogy, 9, 239-243.

Pahkalian, V. E. (2002). What should be a psychologist working in the education system? Questions of psychology, 6, 103-112.

Pahkalian, V. E. (2003). Psychoprophylaxis in practical psychology of education (p. 208). M: PER SE.

Raigorodsky, D. et al. (2000). Psychology of consciousness a reader (p. 235). Samara.

Rubtsov, V. V., Dubrovin, I., Zabrodin, Y. M., Metelkova, H., Romanova, Y. S., \& Semkin, V. V. (2007). The concept of development of the system of psychological support (psychological services) education in the Russian Federation for the period up to 2010. Psychological science and education, 1, 69-82.

Salikhova, N. R. (2013). Characteristics of Personal Value-meaning Systems: A Comparative Study of American and Russian University. Procedia-Social and Behavioral Sciences, 86, 349-354. http://dx.doi.org/10.1016/j.sbspro.2013.08.577

Zabrodin, Y. M., Leonov, O. I., Melentieva, O. S., \& Perepechenova, O. M. (2013). ON the development of the professional standard of the teacher-psychologist, psychologist in education (explanatory note to the professional standard). Bulletin of the Educational and methodological Association of Russian universities for psycho-pedagogical education, 2, 21-41.

Zabrodin, Y. M., \& Sosnowski, B. A. (1989). Motivational and semantic relationships in the structure of the direction of the person. Questions of psychology, 6, 34-42.

\section{Copyrights}

Copyright for this article is retained by the author(s), with first publication rights granted to the journal. This is an open-access article distributed under the terms and conditions of the Creative Commons Attribution license (http://creativecommons.org/licenses/by/3.0/). 